\title{
Project Management for complex ground-based instruments: MEGARA plan
}

\author{
María Luisa García-Vargas ${ }^{\mathrm{a}}$, Ana Pérez-Calpena ${ }^{\mathrm{a}}$, Armando Gil de Paz ${ }^{\mathrm{b}}$, Jesús Gallego ${ }^{\mathrm{b}}$, Esperanza \\ Carrasco $^{c}$, Raquel Cedazo ${ }^{\mathrm{d}}$ and Jorge Iglesias ${ }^{\mathrm{e}}$ \\ ${ }^{a}$ FRACTAL S.L.N.E, C/Tulipán 2, p13-1A, E-28231 Las Rozas, Madrid, Spain; ${ }^{b}$ Departamento de \\ Astrofísica y CC. de la Atmósfera, Facultad de Ciencias Físicas, Universidad Complutense de

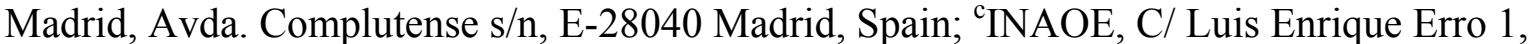 \\ Tonantzintla, Puebla, México; ${ }^{\mathrm{d}}$ Departamento de Electrónica, Automática e Informática Industrial \\ (ELAI), Escuela Técnica Superior de Ingeniería y Diseño Industrial (ETSIDI), Universidad \\ Politécnica de Madrid (UPM), Ronda de Valencia, 3, E-28012, Madrid, Spain; ${ }^{\mathrm{e}}$ Instituto de \\ Astrofísica de Andalucía (IAA-CSIC), Glorieta de la Astronomía s/n, E-18008, Granada, Spain
}

\begin{abstract}
The project management of complex instruments for ground-based large telescopes is a challenge itself. A good management is a clue for project success in terms of performance, schedule and budget. Being on time has become a strict requirement for two reasons: to assure the arrival at the telescope due to the pressure on demanding new instrumentation for this first world-class telescopes and to not fall in over-costs. The budget and cash-flow is not always the expected one and has to be properly handled from different administrative departments at the funding centers worldwide distributed. The complexity of the organizations, the technological and scientific return to the Consortium partners and the participation in the project of all kind of professional centers working in astronomical instrumentation: universities, research centers, small and large private companies, workshops and providers, etc. make the project management strategy, and the tools and procedures tuned to the project needs, crucial for success.

MEGARA (Multi-Espectrógrafo en GTC de Alta Resolución para Astronomía) is a facility instrument of the 10.4m GTC (La Palma, Spain) working at optical wavelengths that provides both Integral-Field Unit (IFU) and Multi-Object Spectrograph (MOS) capabilities at resolutions in the range $\mathrm{R}=6,000-20,000$. The project is an initiative led by Universidad Complutense de Madrid (Spain) in collaboration with INAOE (Mexico), IAA-CSIC (Spain) and Universidad Politécnica de Madrid (Spain). MEGARA is being developed under contract with GRANTECAN.
\end{abstract}

Keywords: MEGARA, MANATEE, GTC, GRANTECAN, project, management, budget, schedule

\section{INTRODUCTION}

\subsection{MEGARA, the new spectrograph for the GTC}

MEGARA (Multi-Espectrógrafo en GTC de Alta Resolución para Astronomía) is a facility instrument for the $10.4 \mathrm{~m}$ GTC in the Observatory of Roque de los Muchachos (ORM), La Palma (Canary Islands, Spain). MEGARA works at optical wavelengths and provides both Integral-Field Unit (IFU) and Multi-Object Spectrograph (MOS) capabilities at resolutions in the range $\mathrm{R}=6,000-20,000$. The instrument consists of two units connected through a fiber link $40 \mathrm{~m}$ length, one located at the Folded-Cass (FC) focus, where the two IFUs and the robotic positioners of the MOS are placed and the spectrograph itself placed at the Nasmyth platform, where is kept static. The description of the instrument is exhaustively given in several references devoted to particular subjects: the Overview ${ }^{1}$, the System Engineering plan $^{2}$, design and plans for Fiber Bundles ${ }^{3,4}$, Optics Design ${ }^{5}$ and manufacturing ${ }^{6}$, opto-mechanics ${ }^{7}$ and cryostat design and manufacturing ${ }^{8}$.

The project is an initiative led by Universidad Complutense de Madrid (Spain) in collaboration with Instituto Nacional de Astrofísica, Óptica y Electrónica (INAOE), Mexico, Instituto de Astrofísica de Andalucía (IAA-CSIC), Spain; and

Modeling, Systems Engineering, and Project Management for Astronomy $\mathrm{VI}$, edited by George Z. Angeli, Philippe Dierickx. Proc. of SPIE Vol. 9150, 91500Y

(c) 2014 SPIE - CCC code: 0277-786X/14/\$18 - doi: 10.1117/12.2055935 
Universidad Politécnica de Madrid (UPM), Spain. The technical complexity of the project, the tight budget for such an instrument (6.5M€ from conceptual design to commissioning), complemented by an important in-kind contribution (evaluated in 5.3M€), and the calendar to completion (18 months from CDR to Acceptance at Laboratory and less than 3 years until the end of the commissioning) makes the management strategy a key aspect. This paper describes the plan and the means to keep the project under specifications, on time and within budget.

\section{PROJECT ORGANIZATION, OVERALL PLAN AND TRACKING}

\subsection{Project Organization}

MEGARA is a project led by UCM, in collaboration with INAOE, IAA and UPM. Figure 1 shows the Consortium composition. It has a board with four partners' representatives (one from each institute) plus the PI himself, who has been delegated by the Consortium to make the final decisions. The figure summarizes also the responsibilities in the instrument. Each partner can develop its work by combining their own resources and contracts with external companies.

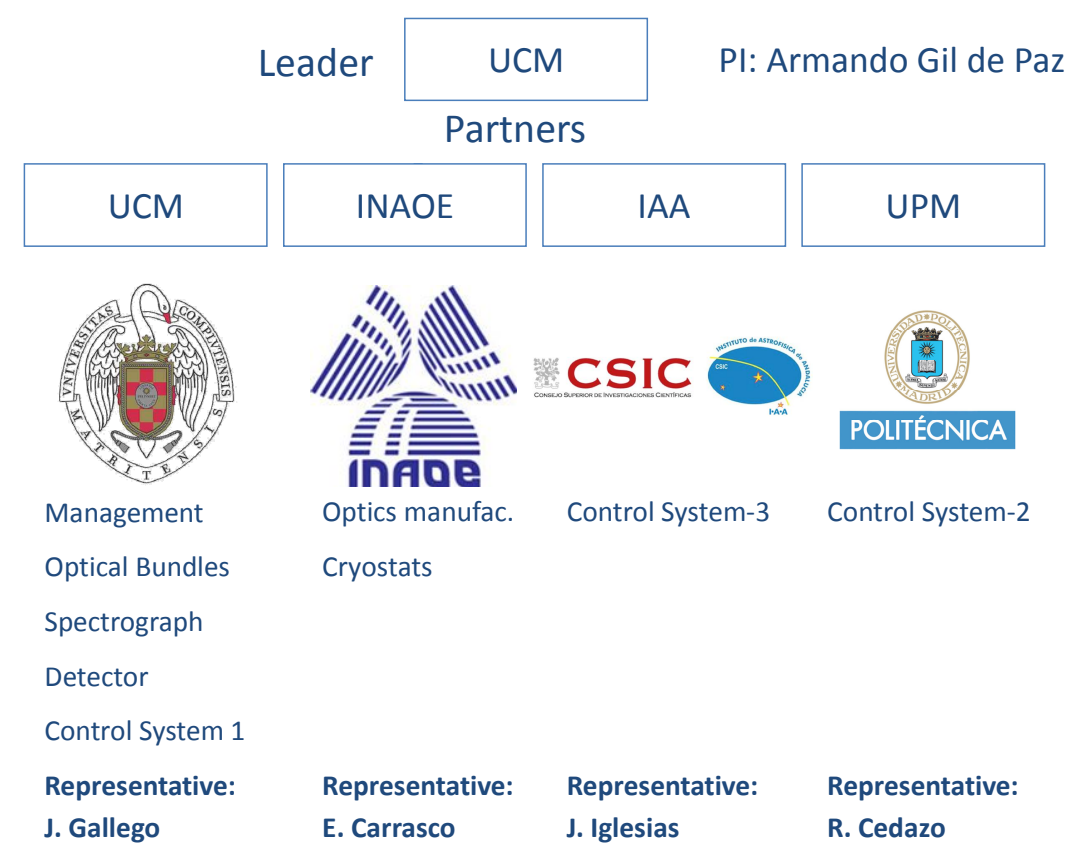

Figure 1. Chart and representatives at the CDR.

Figure 2 shows the project organization. On the top of this organization we have the funding institutes. MEGARA is being developed under contract with GRANTECAN, the public-funded company responsible for the development and operations of the GTC 10-m telescope in the Observatory of Roque de los Muchachos (ORM), La Palma (Canary Islands, Spain). In addition to GTC funding, MEGARA is possible thanks to the in-kind contributions of the Consortium partners, only partly compensated with Guaranteed Time (301 hours). The communication with GRANTECAN is done through the Principal Investigator (PI), who is supported by the Consortium.

MEGARA has also a wide Science team, organized in different groups according to specific topics. Below the PI, we have the MEGARA instrument team, led by the Project Manager, with the responsibility of making the day-to-day decisions needed to keep the project on track under the conditions of the scope, schedule and budget restrictions from the partners and from the contractual clauses with GRANTECAN (both channelized through the PI).

The set of tasks managed by the same overall responsible, oriented to produce a single deliverable or to offer certain kind of services to the project are called Work Packages. In the case of MEGARA, the work for the WPs has been divided by the nature of the tasks to do (fitted to the skills of the people that carry them out) and by organizational needs. Therefore 
WP 10 is led by UCM, including the contributions to the Control System by UPM and IAA; WP 8 and WP 9 are carried out completely in INAOE. WP 8 includes the manufacturing of all optical elements (field lens, collimator and camera lenses, windows and prisms for pupil elements), and the design, construction and tests of the collimator and camera optomechanics. WP 9 contains all the tasks to the design, manufacturing, integration and tests of the cryostat. MEGARA has included in the instrument team from the beginning of the project two technological Spanish companies: AVS, responsible for the design and development of the Fiber MOS (WP 5), and FRACTAL, responsible for Management (WP 1), System Engineering (WP 2); the design and tests of the Optical Bundles (WP 6) and the Spectrograph (WP 7), in this latter case except the tasks carried out by INAOE in WP 8 and 9. Finally, WP 11 is being done at UCM and includes all the tasks to integrate and test the instrument at the Laboratory of Advance Instrumentation (whose acronym is LICA in Spanish) and shall be carried out by all groups at different phases, being the overall Assembly, Integration and Verification (AIV) Plan under the technical execution of the System Engineer ${ }^{2}$.

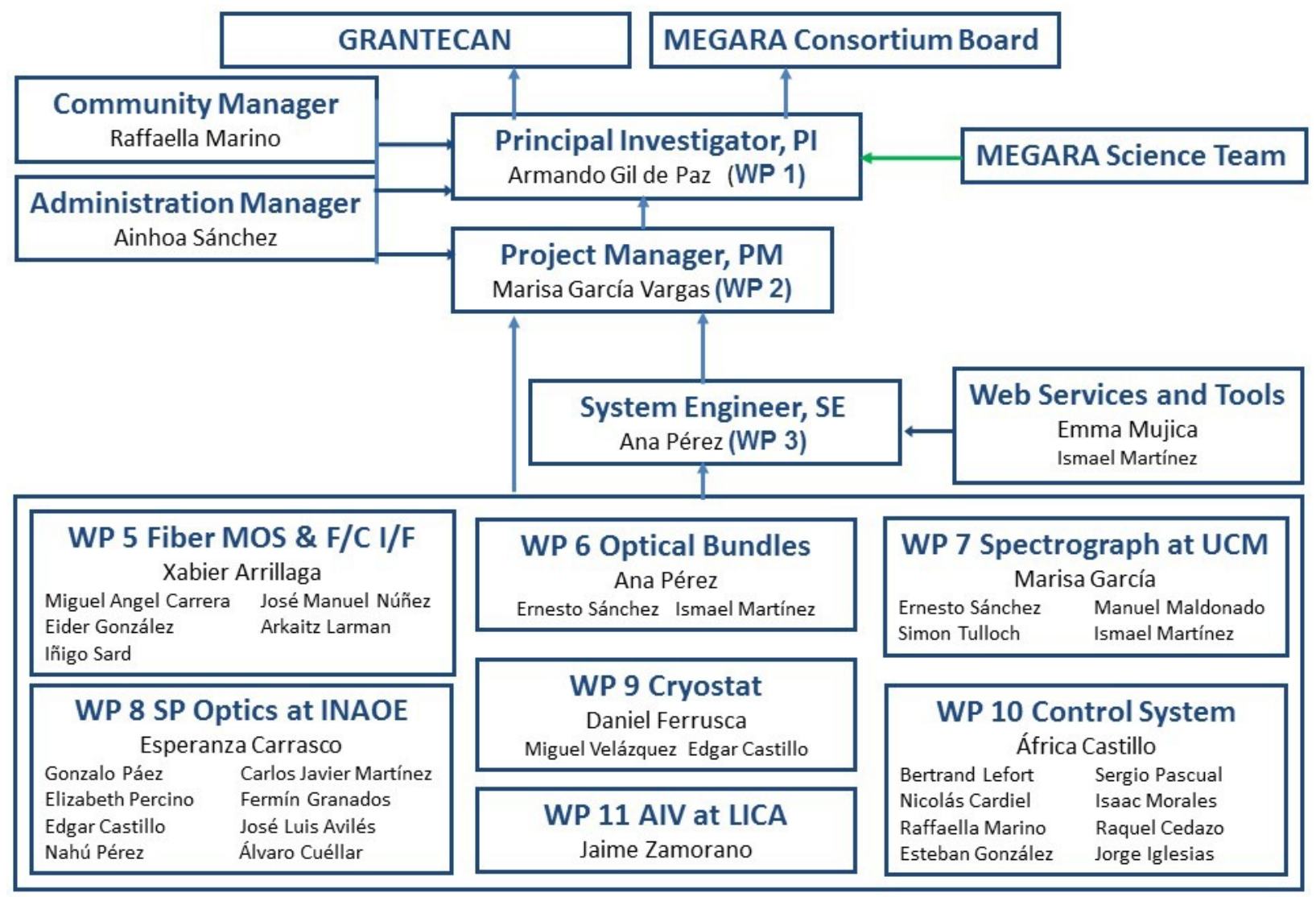

Figure 2. Project Organization at the Critical Design Review.

Each Work Package has an associated set of deliverables and has been divided in tasks, smaller pieces of work, and all together constitutes the Work Breakdown Structure, WBS. These tasks have been detailed by the Project Manager together with the WP managers. To develop all these tasks, and in addition to AVS and FRACTAL, there are other companies with key contributions in the project: ATI-SEDI, for the bundles manufacturing; AMUS for the microlenses; OHARA and Hellma for the blanks, Wasatch Photonics for the VPH gratings and e2V for the detector. In addition to these main sub-contractors there are many other providers. The current plan includes all the input from these companies based on updated firm-fixed price/schedule quotations. 


\subsection{MANATEE, a tool for project tracking}

All projects must be defined in terms of Scope (Performance), Schedule (calendar a time relationships among tasks) and Price (overall budget and cash-flow along the project). These three parameters must be planned from the beginning of a project, but the real difficulty appears when trying to control them and their inter-relationships as far as the project progresses. The core management activities are usually a huge amount of day-to-day tasks related to making decisions, managing and coordinating the team that could lead to a provisional abandon of the crucial project control task. MEGARA plan is being tracked with MANATEE ${ }^{10}$, a powerful web-based tool property of FRACTAL, which organizes the complete information of the project in a database. MANATEE has been designed to help in the optimization of the project achievement, acting as an electronic project controller able to be fed by the team members and to inform them on the project progress, generating also warnings when important deviation from the planned goal are detected.

MANATEE is part of the FRACTAL System and Project Suite ${ }^{9}$, which includes also the tools GECO (System Engineering and Configuration Tool), DOCMA (Documentation Management Tool) and SUMO ${ }^{11}$ (operations and maintenance of scientific facilities). In order to minimize the maintenance costs and complexity, Fractal Suite has been developed in a platform-independent technology; providing simple ways to install the software in a distributed environment and implement a user access policy and encryption features to protect the project's data. Fractal Suite tools are being successfully applied to carry out international projects mainly on astronomical instruments and telescopes.

MEGARA project office is geographically distributed and the project is complex, in terms of number of disciplines, resources, funding sources, etc. so this web-based software tool allows people being more active in the project and keep them fully informed on the project status taken into account their roles and therefore permissions in the project. The tool archives relevant information like WPs and WBSs definition, Deliverable reports, Milestones, Cash Milestones, WBS Progress Reports, Budget items, Purchase Orders, Actions, Non-conformance, risks, etc. references

\section{SCOPE}

MEGARA has been fully defined and a coherent detailed design for all the subsystems had been presented at the time of the CDR. The instrument is based on a Fiber Unit system, coupled to the telescope at the Folded-Cass focus, with three main modes: LCB, MOS (fully funded) and SCB (funds not available yet), and one spectrograph (located on the Nasmyth platform) providing three spectral resolutions, with 6 Low-Resolution (LR), 10 Mid-Resolution (MR) and 2 High Resolution (HR) elements, covering the whole wavelength range at low and mid resolution. MEGARA has been designed with known solutions and no major risks either shop-stoppers have been identified. In addition to the complete design documentation and drawings, procedures and manuals, the deliverables to the telescope are MEGARA instrument itself, plus the tools needed to install and operate the instrument. Spares have been identified but their purchase is out of the contract's scope and shall be acquired directly by GRANTECAN. The specifications of all subsystems have been prepared and the interfaces with the telescope and among MEGARA subsystems are closed. All these requirements have been archived in a database and are submitted to configuration for scope and performance control. Procedures for documentation, product tree and configuration identification, specifications and their control, configuration changes, non-conformance, anomalies, actions and risks have been included in the System Engineering Plan and procedures ${ }^{2}$.

\section{BUDGET}

MEGARA is a co-funded project by GRANTECAN and by MEGARA Consortium. The total project budget adding the money to the in-kind contribution converted in $€$ is $11.8 \mathrm{M} €$. The total money needed for the project from conceptual design to the end of the commissioning is $6.502 \mathrm{M} €$, including a contingency of $0.43 \mathrm{M} €$. The presented budget has a high degree of reliability since $90 \%$ of the budget is based in firm fixed quotations and final committed price of the engineering services of both companies and partners. The money received in previous phases from GRANTECAN was 1.41 M€. The current contract covers 4.49 M€, so that we have a deficit of $0.61 \mathrm{M} €$ to be got to finish the project (this amount could be partially reduced as an expense of the contingency). The complete instrument has to be delivered within the contractual obligations, with the exception of the SCB hardware (included in the total budget but not requested by GTC). The SCB costs $0.14 \mathrm{M} €$ so that at least $0.5 \mathrm{M} €$ is still missing. A recovery plan is being carried out by the PI supported by the UCM, looking for additional funds coming from the central Ministry, the Local Government and/or 
European Funds. This money will be used to cover part of the human resources expenses in 2016 and 2017, being getting this money the major budgetary risk in the project.

The in-kind contribution is estimated and justified by the Consortium in 5.3M€ (when including the same level of contingency, $7.5 \%$, that for the money). This amount of money corresponds to $45 \%$ of the total project budget. When converting this money in Guaranteed Time according to GRANTECAN's rule (220 hours per million euro), the equivalent GT would be 1166 hours, having requested the Consortium only the 660 hours offered at the time of the AoO. The final awarded GT has been of 301.28 hours (equivalent to a contribution of 1.37M€).

The major project driver that has determined (and determines) the project parameters and in particular the schedule and consequently the overall budget is an appropriate cash flow for the funds. The payment milestones in the contract with GRANTECAN have been traced to the project expenses and the money from each of these payments has been preassigned. Any deviation of delay in receiving the funds could lead to a project delay and/or over-cost.

\section{CALENDAR}

Table 1 summarizes the main milestones along the path to the operation.

Table 1. MEGARA Calendar. Main Phases and Review Control Milestones

\begin{tabular}{|c|c|c|c|}
\hline Name & Start & End & Review \\
\hline Feasibility Studies & 04-03-2009 & $31-10-2009$ & \\
\hline \multirow{2}{*}{ Conceptual Design } & $01-11-2010$ & $21-07-2010$ & \\
\hline & \multicolumn{2}{|c|}{ System Conceptual Design Review, SCDR } & $21-07-2010$ \\
\hline \multirow[t]{4}{*}{ Preliminary Design } & 01-10-2010 & $30-09-2012$ & \\
\hline & \multicolumn{2}{|c|}{ Preliminary Design Review, PDR } & $20-03-2012$ \\
\hline & \multicolumn{2}{|l|}{ Delta-PDR passed } & 21-09-2012 \\
\hline & \multicolumn{2}{|c|}{ Optics CDR - OCDR passed } & $02-05-2013$ \\
\hline \multirow[t]{3}{*}{ Detailed Design } & 01-10-2012 & $31-07-2014$ & \\
\hline & \multicolumn{2}{|c|}{ Critical Design Review, CDR } & $10-06-2014$ \\
\hline & \multicolumn{2}{|l|}{ CDR closed } & $31-07-2014$ \\
\hline \multirow[t]{2}{*}{ Manufacturing and subsystem tests } & $01-12-2013$ & $30-09-2015$ & \\
\hline & \multicolumn{2}{|c|}{ Subsystem Acceptance Reviews, SSAR } & $30-09-2015$ \\
\hline \multirow[t]{3}{*}{ Assembly, Integration and Verification } & $01-12-2014$ & $28-02-2016$ & \\
\hline & \multicolumn{2}{|c|}{ Preparation for MEGARA Acceptance closed } & 02-03-2015 \\
\hline & \multicolumn{2}{|c|}{ Laboratory Acceptance Review, LAR } & $28-02-2016$ \\
\hline \multirow[t]{4}{*}{ Integration and Commissioning at the GTC } & $01-12-2016$ & $30-04-2017$ & \\
\hline & \multicolumn{2}{|c|}{ MEGARA integrated at the GTC } & $31-12-2016$ \\
\hline & \multicolumn{2}{|c|}{ Provisional Acceptance, PA } & $30-04-2017$ \\
\hline & \multicolumn{2}{|c|}{ Final Acceptance, FA } & $30-04-2018$ \\
\hline
\end{tabular}


MEGARA started as a response led by UCM to an Announcement of Opportunity launched by GRANTECAN in 2009 , and open to the GTC partner institutes (all from Spain and Mexico and University of Florida), to build the next multiobject mid-resolution for the telescope. MEGARA won the competition and since then to now, the instrument has passed several phases and reviews under different contracts with GRANTECAN, being fully approved for construction in September 2012 after delta-PDR, and prioritized for being fully funded in 2013, after the GTC Instrumentation Review.

MEGARA is being developed under a construction contract with GRANTECAN signed in April 2014, covering the detailed design, manufacturing and commissioning. In the moment of writing this paper, the instrument has just delivered the Critical Design Review documentation package to the GTC. We discuss the schedule of the different WPs.

\subsection{WP 5: Fiber MOS and Focal Adapter}

WP 5 develops the Fiber MOS and Focal Adapter, which will be carried out under contract with AVS. All the drawings and plans and ready for starting manufacturing. Figure 3 shows the Gantt chart of this Work Package.

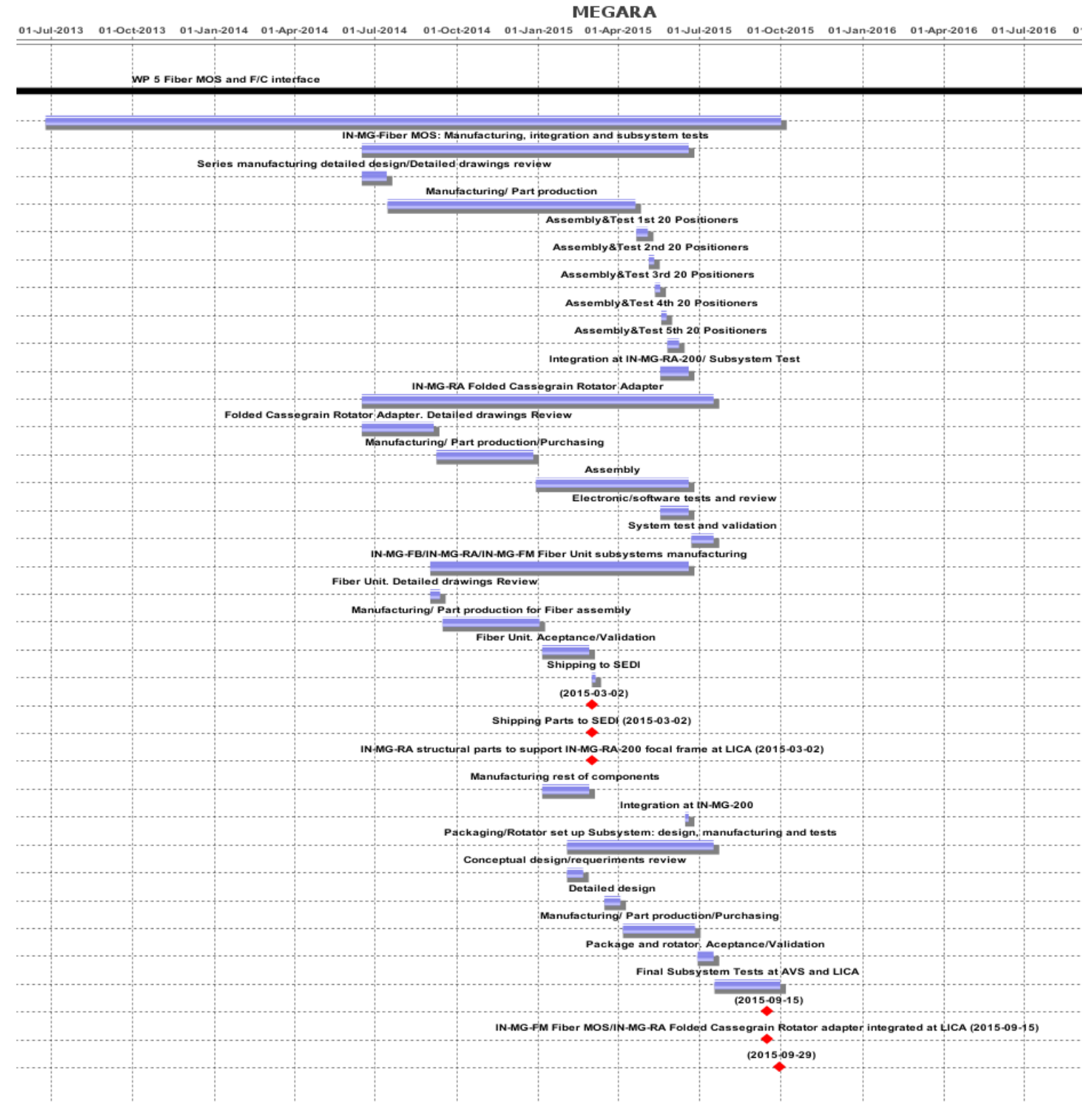

Figure 3. Fiber MOS and Focal Adapter Gantt chart. Planning from CDR to delivery 
The work has been divided in 4 main sub-work-packages associated to manufacture and tests the corresponding subsystems: The Fiber MOS itself, the Folded-Cassegrain Rotator Adapter, the Fiber Units (buttons, pseudo-slits and frames) and the Packaging and Rotator subsystem, which supports the complete Folded-Cassegrain Rotator Adapter and Fiber MOS during the transportation (from AVS to UCM, and from UCM to ORM) and also during the final AIV phase in Madrid (in the last quarter of 2015) where the complete subsystem is needed for testing MEGARA functionality with the Fiber MOS in use. All these sub-work-packages run in parallel and inside each of these sub-work-packages the tasks are running in sequence. The longest one, and therefore in the critical path of the subsystem delivery is the manufacturing and tests of the 100 positioners, which will be manufactured in series of 20 units.

\subsection{WP 6: Optical Bundles}

WP 6 tracks the Optical Bundles. This WP contains: (a) The Large Compact Bundle (LCB) composed by the central bundle plus 8 fixed mini-bundles whose placed at the borders of the F/C MEGARA FOV, whose fibers will be integrated in the same pseudo-slit than the LCB for sky-subtraction purpose and (b) The Multi-Object Spectroscopy (MOS) bundle, composed by 92 mini-bundles corresponding to 92 moving positioners in the Fiber MOS and mounted together in the MOS pseudo-slit. In addition the Consortium is looking for funding the Small Compact Bundle (SCB), which is fully design and ready to be manufactured if the money is found. The Gantt chart is presented in Figure 4.

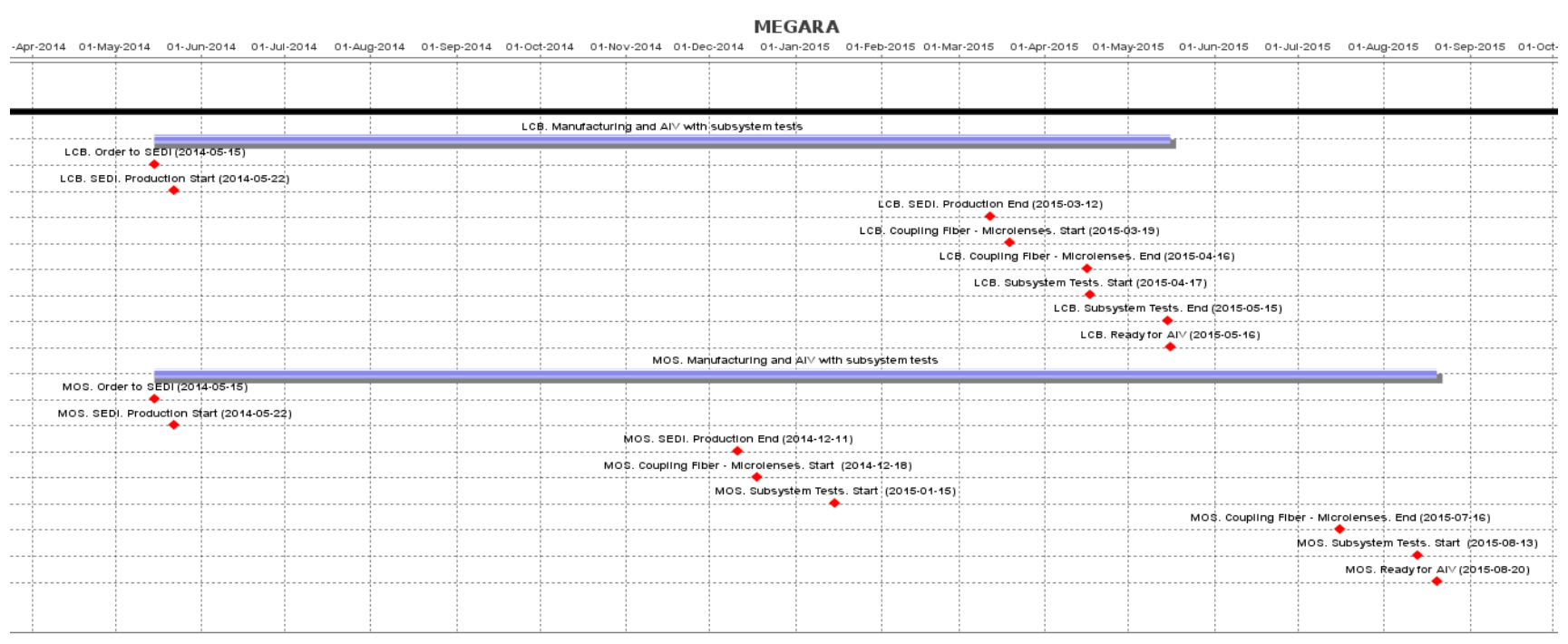

Figure 4. Optical Bundles. Planning from CDR to delivery

The fiber bundles will be contracted to SEDI while the microlens arrays will be contracted to AMUS. Specifications and detailed drawings were frozen at the time of the OCDR. There is a precise coordinated plan among FRACTAL (design and assembly), AVS (who builds the buttons, pseudo-slits and plates) and SEDI (who does the bundle and polishes the fibers). Some prototypes are being built for gluing microlenses and fibers. Two MOS bundles, with and without microlenses, will be tested. Additionally, a LCB microlens array will be assembled to a dummy plate to essay the procedure. These tests will be done before the integration of the microlenses and fibers in the final bundles. Once the microlenses and fibers will be coupled, an exhaustive series of tests will be carried out at LICA to characterize them.

\subsection{WP 7: Spectrograph tasks at UCM}

WP 7 includes the tasks related to optics, the spectrograph mechanics and mechanisms, the pupil element optomechanics and the Detector and Acquisition System (DAS). Regarding the Optics, the plan is fully linked to the arrival of the pupil elements, which will be tested individually and then coupled to the prisms (in the case of MR and HR). Also, the order-sorting filter will be purchased but we have included this milestone as part of the shutter task.The opto- 
mechanics for the pupil element mounts is at the level of a complete set of drawings and ready to manufacture. The plan is to manufacture one unit of each type, assembly, and then order the rest of them.

The subsystems included in the Spectrograph Mechanics and mechanisms are the optical bench, the pseudo-slit focusing mechanism, the pseudo-slit exchange mechanism, the shutter mechanism and the wheel pupil mechanism. Other minor components like the interfaces to the optical bench and the pseudo-slit support will be manufactured at UCM workshop or any other workshop in Madrid. The current plan is consistent with having the mechanics and mechanisms integrated at LICA by the beginning of March 2015. The integration and tests will be carried out directly with the final Mechanisms Control System, which will be planned to have the needed functionality by the time of each component will arrive. We have crossed the plans of mechanisms and control system to assure that the required functionality will be on time.

Regarding the DAS, the e $2 \mathrm{~V}$ detector will be ordered immediately after the reception of the first payment of the construction contract. During 2013 and 2014, the team has characterized an identical unit for another project so everything is prepared at LICA to characterize the detector as soon as it arrives. Together with the detector we will order a new copy of the CCD controller and electronic components, although all these elements exist already at LICA since they were bought with UCM infrastructure funds in 2012 and 2013.Finally, the DAS shall be integrated with the cryostat as soon as the cryostat arrives at Madrid. Some tests with a flat fused-silica window shall be performed. Then, the cryostat with the DAS shall be integrated with the camera for the MEGARA spectrograph integration and alignment.

\subsection{WP 8: Spectrograph Optics at INAOE}

Collimator Optics and opto-mechanics manufacturing is being carried out in Mexico under INAOE supervision. Two CONACYT centers are working for MEGARA: INAOE and CIO, with the tasks divided as follows although always under the supervision and responsibility of INAOE.

INAOE will be responsible for (a) managing and coordinating the whole WP; (b) blanks reception and tests; (c) shipping blanks to CIO for those lenses to be polished at CIO; (d) shipping polished lens at INAOE to CIO for coating; (e) design and manufacture appropriate boxes and containers for optical elements; (f) polishing of the following optical elements: collimator lenses COLL-S1, COLL-D2, COLL-D3, camera lens CAM-S7, BK7 dummy prisms; thick (BK7) and thin (FS) cryostat test windows; and all prisms (MR and HR); (g) shipping all tested windows pairs to Wasatch Photonics; (h) shipping all tested prisms to UCM; (i) manufacture and tests all parts of collimator opto-mechanics; (j) manufacture and tests all parts of camera opto-mechanics; (k) integrate and test collimator and camera assemblies (optics and opto.mechanics); (1) shipping collimator and camera subsystems fully tested to UCM

CIO will be responsible for (a) blank reception of those elements to be polished at CIO; (b) coating of all optical elements (except windows for MR and HR - uncoated); (c) shipping all coated elements to INAOE; (d) polishing of the Field Lens; (e) polishing of the following elements: collimator lenses COLL-D4, COLL-D5, camera lenses CAM-D1, CAM-D2, CAM-D3, CAM-D4, CAM-S5, CAM-S6 and all flat windows for pupil elements (LR, MR and HR).

We have developed a project plan with several thousands of control milestones for Optics tracking and a weekly telecon (Every monday at 8pm CET) between WP8 manager and the project manager (also WP7 manager) is carrying out to track the progress and to make the appropriate decisions to keep the critical path activities on time.

All milestones have been introduced in MANATEE together with the links among them. This has been done for the main subsystems and components to be manufactured. We have selected some main subsystems to show in the next lines the level of detail and control of the optical manufacturing plan.

Each lens has its own planning. The plan includes the following activities: (a) blank ordering and reception; (b) blank inspection and tests; (c) first check point: blank report and labels for further identification; (d) tooling preparation; (e) manufacturing (polishing and quality control); (f) second check point: Documentation after polishing; (g) coating design and test samples; (h) coating, (i) third check point: documentation after coating; (j) shipping between INAOE and CIO according to the task to be done (this is done by staff drivers with high safety measurements for these transportations).In addition, those lenses that have to be cemented have the tasks associated to the cementing samples tests and the cementing process itself. This has been done for each lens. MANATEE can automatically update the children milestones when the parent milestone changes. As an example, Figure 5 shows the MANATEE output exported in an xls file showing the main milestones for COLL-D3 lens manufacturing calendar and the linked milestones. This kind of planning exists for each of the 5 collimator lenses and 7 camera lenses. We have included three checkpoints during the process to assure the quality control during the process. Non-Conformances, should they appear, are considered after 
studying the impact on the optical design. We will update the optical design several times after having polished the lens and with the real as-built values. This is one of the advantages of having the polishing activities within the Consortium.

\begin{tabular}{|c|c|c|c|}
\hline Date & Name & Parent date & Parent name \\
\hline 2013-03-25 & OP: FAB-INAOE. Collimator. COLL-D3 (BSM51Y) blank at INAOE & & \\
\hline 2013-05-06 & OP: FAB-INAOE. Collimator. COLL-D3 (BSM51Y). Start Tooling Preparation & & \\
\hline 2013-07-19 & $\begin{array}{l}\text { OP: FAB-INAOE. Collimator. COLL-D3 (BSM51Y). End of Tooling } \\
\text { Preparation }\end{array}$ & & \\
\hline 2013-08-12 & OP: FAB-INAOE. Collimator. COLL-D3 (BSM51Y). Start Manufacturing & & \\
\hline 2013-09-16 & $\begin{array}{l}\text { OP: FAB-CIO. Coating. Design and tests. Start. BB. BSM51Y. Collimator. } \\
\text { COLL-D3 }\end{array}$ & & \\
\hline 2014-04-30 & $\begin{array}{l}\text { OP: FAB-CIO. Coating. Design and tests. End. BB. BSM51Y. Collimator. } \\
\text { COLL-D3. }\end{array}$ & & \\
\hline 2014-05-08 & OP: FAB-INAOE. Collimator. COLL-D3 (BSM51Y). End of Manufacturing & & \\
\hline 2014-05-09 & OP: FAB-INAOE. Collimator. COLL-D3 (BSM51Y). Shipping to CIO & 2014-05-08 & OP: FAB-INAOE. Collimator. COLL-D3 (BSM51Y). End of Manufacturing \\
\hline 2014-05-11 & OP: FAB-CIO. Collimator. COLL-D3 (BSM51Y). Arrival at CIO & 2014-05-09 & OP: FAB-INAOE. Collimator. COLL-D3 (BSM51Y). Shipping to CIO \\
\hline \multirow[t]{2}{*}{ 2014-05-12 } & OP: FAB-CIO. Collimator. COLL-D3 (BSM51Y). Start Coating & 2014-05-11 & OP: FAB-CIO. Collimator. COLL-D3 (BSM51Y). Arrival at CIO \\
\hline & & 2014-04-30 & $\begin{array}{l}\text { OP: FAB-CIO. Coating. Design and tests. End. BB. BSM51Y. Collimator. } \\
\text { COLL-D3. }\end{array}$ \\
\hline 2014-05-26 & OP: FAB-CIO. Collimator. COLL-D3 (BSM51Y). End Coating & 2014-05-12 & OP: FAB-CIO. Collimator. COLL-D3 (BSM51Y). Start Coating \\
\hline 2014-05-27 & OP: FAB-CIO. Collimator. COLL-D3 (BSM51Y). Lens ready & 2014-05-26 & OP: FAB-CIO. Collimator. COLL-D3 (BSM51Y). End Coating \\
\hline 2014-05-28 & OP: FAB-CIO. Collimator. COLL-D3 (BSM51Y). Shipping to INAOE & 2014-05-27 & OP: FAB-CIO. Collimator. COLL-D3 (BSM51Y). Lens ready \\
\hline 2014-05-31 & OP: OP: FAB-INAOE. Collimator. COLL-D3 (BSM51Y). Arrival at INAOE & 2014-05-28 & OP: FAB-CIO. Collimator. COLL-D3 (BSM51Y). Shipping to INAOE \\
\hline \multirow[t]{2}{*}{ 2014-06-01 } & $\begin{array}{l}\text { OP: FAB-INAOE. Collimator. Cementing Tests. COLL-D2 (PBM2Y) / COLL- } \\
\text { D3 (BSM51Y). Start }\end{array}$ & 2014-05-31 & OP: FAB-INAOE. Cementing Epoxy Arrival \\
\hline & & 2014-01-10 & OP: FAB-INAOE. Cementing Large Samples. Arrival \\
\hline 2014-06-22 & $\begin{array}{l}\text { OP: FAB-INAOE. Collimator. Cementing Tests. COLL-D2 (PBM2Y) / COLL- } \\
\text { D3 (BSM51Y). End }\end{array}$ & 2014-06-01 & $\begin{array}{l}\text { OP: FAB-INAOE. Collimator. Cementing Tests. COLL-D2 (PBM2Y) / COLL- } \\
\text { D3 (BSM51Y). Start }\end{array}$ \\
\hline \multirow[t]{3}{*}{ 2014-06-24 } & $\begin{array}{l}\text { OP: FAB-INAOE. Collimator. Start Cementing COLL-D2 (PBM2Y) / COLL-D3 } \\
\text { (BSM51Y) }\end{array}$ & $2014-06-22$ & $\begin{array}{l}\text { OP: FAB-INAOE. Collimator. Cementing Tests. COLL-D2 (PBM2Y) / COLL- } \\
\text { D3 (BSM51Y). End }\end{array}$ \\
\hline & & 2014-05-31 & OP: OP: FAB-INAOE. Collimator. COLL-D3 (BSM51Y). Arrival at INAOE \\
\hline & & 2014-06-03 & OP: FAB-INAOE. Collimator. COLL-D2 (PBM2Y). Arrival at INAOE \\
\hline 2014-07-01 & $\begin{array}{l}\text { OP: FAB-INAOE. Collimator. End of Cementing COLL-D2 (PBM2Y) / COLL- } \\
\text { D3 (BSM51Y) }\end{array}$ & 2014-06-24 & $\begin{array}{l}\text { OP: FAB-INAOE. Collimator. Start Cementing COLL-D2 (PBM2Y) / COLL-D3 } \\
\text { (BSM51Y) }\end{array}$ \\
\hline
\end{tabular}

Figure 5. MANATEE output exported in an xls file. Collimator COLL-D3 element. Schedule detail and links.

For each Collimator and Camera main subsystem (Optics and Opto-mechanics) we have identified the critical path. This critical path is automatically calculated by MANATEE after taking into account all the possible paths to arrive to a certain date according to the links introduced among the milestones. The critical path of the Collimator main Optics is shown in Figure 6. Columns one and two of the table show the date and title of the milestones respectively, which belong to the critical path to arrive to a certain milestone (in this example is the moment in which the complete Collimator Optics is finished). Column 3 gives the more limiting date and in a light color we can find below other milestones linked to the one in the critical path to be able to analyze what other threads can impact the critical path. The Collimator Optics critical path is mainly driven for the aspheric surface manufacturing (COLL-S1) that required the order of a CGH hologram to be able to fabricate the surface. The total length of this chain is 215 days.

If we look to the first milestone, this is linked to three dates: the availability of COLL-S1 fully finished, the availability of COLL-D2/COLL-D3 and the availability of COLL-D4/COLL-D5. However, these two milestones are far away from the critical path by more than 3 and 4 months respectively. This indicates that this COLL-S1 plan has to be closely tracked and its tasks have to have the highest priority (considering the Collimator Optics only). The same kind of study for the Collimator as a whole (Optics and Opto-mechanics, Figure 7) shows that the collimator critical path is driven by the opto-mechanics (being the Optics ready more than 2 months in advance). And the opto-mechanics manufacturing has been driven by the funds availability (or the lack of them until the construction-contract signature). 


\begin{tabular}{|c|c|c|c|c|}
\hline Date & Name & Parent date & Parent name & length (days) \\
\hline \multirow[t]{3}{*}{ 2014-10-13 } & OP: AIV-INAOE. Collimator. Optics ready for AIV & 2014-10-12 & OP: FAB-INAOE. Collimator. COLL-S1 (PBM2Y). Arrival & 1 \\
\hline & & 2014-07-12 & $\begin{array}{l}\text { OP: FAB-INAOE. Collimator. End of Cementing COLL-D4 } \\
\text { (PBM8Y) / COLL-D5 (CaF2) }\end{array}$ & 93 \\
\hline & & 2014-06-11 & $\begin{array}{l}\text { OP: FAB-INAOE. Collimator. End of Cementing COLL-D2 } \\
\text { (PBM2Y)/ COLL-D3 (BSM51Y) }\end{array}$ & 124 \\
\hline 2014-10-12 & OP: FAB-INAOE. Collimator. COLL-S1 (PBM2Y). Arrival & 2014-10-10 & $\begin{array}{l}\text { OP: FAB-CIO. Collimator. COLL-S1 (PBM2Y). Ship to } \\
\text { INAOE }\end{array}$ & 2 \\
\hline 2014-10-10 & $\begin{array}{l}\text { OP: FAB-CIO. Collimator. COLL-S1 (PBM2Y). Ship to } \\
\text { INAOE }\end{array}$ & 2014-10-09 & OP: FAB-CIO. Collimator. COLL-S1 (PBM2Y). Lens ready & 1 \\
\hline 2014-10-09 & $\begin{array}{l}\text { OP: FAB-CIO. Collimator. COLL-S1 (PBM2Y). Lens } \\
\text { ready }\end{array}$ & 2014-10-08 & OP: FAB-CIO. Collimator. COLL-S1 (PBM2Y). End Coating & 1 \\
\hline 2014-10-08 & $\begin{array}{l}\text { OP: FAB-ClO. Collimator. COLL-S1 (PBM2Y). End } \\
\text { Coating }\end{array}$ & 2014-10-01 & OP: FAB-CIO. Collimator. COLL-S1 (PBM2Y). Start Coating & 7 \\
\hline \multirow[t]{3}{*}{ 2014-10-01 } & $\begin{array}{l}\text { OP: FAB-CIO. Collimator. COLL-S1 (PBM2Y). Start } \\
\text { Coating }\end{array}$ & 2014-09-30 & OP: FAB-CIO. Collimator. COLL-S1 (PBM2Y). Arrival at $\mathrm{CIO}$ & 1 \\
\hline & & $2013-12-15$ & $\begin{array}{l}\text { OP: FAB-CIO. Coating. Design and tests. End. BB. PBM2Y. } \\
\text { Collimator. COLL-S1 }\end{array}$ & 290 \\
\hline & & $2014-09-25$ & $\begin{array}{l}\text { OP: FAB-INAOE. Collimator. COLL-S1 (PBM2Y). End of } \\
\text { Manufacturing }\end{array}$ & 6 \\
\hline 2014-09-30 & $\begin{array}{l}\text { OP: FAB-CIO. Collimator. COLL-S1 (PBM2Y). Arrival at } \\
\text { CIO }\end{array}$ & $2014-09-28$ & $\begin{array}{l}\text { OP: FAB-INAOE. Collimator. COLL-S1 (PBM2Y). Ship to } \\
\text { CIO }\end{array}$ & 2 \\
\hline 2014-09-28 & $\begin{array}{l}\text { OP: FAB-INAOE. Collimator. COLL-S1 (PBM2Y). Ship to } \\
\text { CIO }\end{array}$ & 2014-09-25 & $\begin{array}{l}\text { OP: FAB-INAOE. Collimator. COLL-S1 (PBM2Y). End of } \\
\text { Manufacturing }\end{array}$ & 3 \\
\hline 2014-09-25 & $\begin{array}{l}\text { OP: FAB-INAOE. Collimator. COLL-S1 (PBM2Y). End of } \\
\text { Manufacturing }\end{array}$ & $2014-07-10$ & $\begin{array}{l}\text { OP: FAB-INAOE. Collimator. COLL-S1 (PBM2Y). Start } \\
\text { Manufacturing }\end{array}$ & 77 \\
\hline \multirow[t]{3}{*}{ 2014-07-10 } & $\begin{array}{l}\text { OP: FAB-INAOE. Collimator. COLL-S1 (PBM2Y). Start } \\
\text { Manufacturing }\end{array}$ & 2014-05-11 & OP: FAB-INAOE. Collimator. COLL-S1. CGH at INAOE & 60 \\
\hline & & 2013-03-01 & $\begin{array}{l}\text { OP: FAB-INAOE. Collimator. COLL-S1 (PBM2Y). Start } \\
\text { Tooling Preparation }\end{array}$ & 496 \\
\hline & & $2013-03-25$ & $\begin{array}{l}\text { OP: FAB-INAOE. Collimator. COLL-S1 (PBM2Y) blank at } \\
\text { INAOE }\end{array}$ & 472 \\
\hline 2014-05-11 & OP: FAB-INAOE. Collimator. COLL-S1. CGH at INAOE & 2014-03-12 & $\begin{array}{l}\text { OP: FAB-INAOE. Collimator. COLL-S1. CGH Purchase } \\
\text { order }\end{array}$ & 60 \\
\hline & & & & 215 \\
\hline
\end{tabular}

Figure 6. MANATEE output exported in an xls file. Critical Path for the completion of Collimator Optics (215 days).

\begin{tabular}{|c|c|c|c|c|}
\hline Date & Name & Parent date & Parent name & length (days) \\
\hline 2015-01-29 & OP: AIV-INAOE. Collimator. Ready & $2015-01-28$ & OP: AIV-INAOE. Collimator. End of subsystem tests & 1 \\
\hline 2015-01-28 & OP: AIV-INAOE. Collimator. End of subsystem tests & 2015-01-13 & OP: AIV-INAOE. Collimator. Start of subsystem tests & 15 \\
\hline 2015-01-13 & OP: AIV-INAOE. Collimator. Start of subsystem tests & 2015-01-12 & OP: AIV-INAOE. Collimator. End of Barrel AIV & 1 \\
\hline 2015-01-12 & OP: AIV-INAOE. Collimator. End of Barrel AIV & $2014-12-13$ & OP: AIV-INAOE. Collimator. Start of Barrel AIV & 30 \\
\hline \multirow[t]{2}{*}{ 2014-12-13 } & OP: AIV-INAOE. Collimator. Start of Barrel AIV & $2014-12-12$ & OP: FAB-INAOE. Collimator Barrel Manufacturing. End & 1 \\
\hline & & 2014-10-13 & OP: AIV-INAOE. Collimator. Optics ready for AIV & 61 \\
\hline 2014-12-12 & OP: FAB-INAOE. Collimator Barrel Manufacturing. End & 2014-08-14 & OP: FAB-INAOE. Collimator Barrel Manufacturing. Start & 120 \\
\hline \multirow[t]{2}{*}{ 2014-08-14 } & OP: FAB-INAOE. Collimator Barrel Manufacturing. Start & 2014-08-13 & OP: FAB-INAOE. Collimator barrel. Materials procurement. End & 1 \\
\hline & & 2014-06-30 & CONTRACT: CDR. Process closed & 45 \\
\hline 2014-08-13 & OP: FAB-INAOE. Collimator barrel. Materials procurement. End & 2014-05-15 & OP: FAB-INAOE. Collimator barrel. Materials procurement. Start & 90 \\
\hline & & & & 259 \\
\hline
\end{tabular}

Figure 7. MANATEE output exported in an xls file. Critical Path for the completion of Collimator Subsystem (259 days).

Proc. of SPIE Vol. 9150 91500Y-10 
Finally, the critical path of the whole set (the two assemblies: collimator and camera fully tested that will be shipped together to UCM) is driven by the camera (with a distance of 43 days with the collimator assembly) and going back in time the milestones that condition this path are the ones relative to the opto-mechanics manufacturing that are linked to the money reception. We plan to ship the collimator, the camera and the cryostat assemblies to Madrid (UCM) at the end of March 2015. This arrival is in the critical path of the acceptance at laboratory milestone. We will test the cryostat separately from the camera and for that we had planned the manufacturing of a thick window with the same vacuum sealing that the last camera lens to be able to carry out the cryostat tests. Also, a thin coated fused silica window will be manufactured to allow testing the cryostat and the detector.

The same analysis has been done for the camera. In the moment of writing this paper, the whole camera Optics critical path is driven by the doublet CAM-D1/CAM-D2.

Regarding the pupil elements, the coordination has to be exquisite and carefully planned since the tasks are done in different countries by different teams. We summarize the process for each type of grating element: LR, MR and HR and gives one example as we have presented in the Main Optics case.

LR elements: These elements are composed by two flat windows (polished and coated) with the VPH hologram recorded on one of the windows and sandwiched with the other one. The windows blanks will arrive at INAOE (México), who will test and label the blanks with the part number. Then, the windows will be sent to CIO (México), where they will be polished and coated. The windows will be sent back to INAOE who will validate each pair and ship them to Wasatch Photonics (Utah, USA); the hologram shall be recorded at Wasatch who will send the sandwiched elements to UCM (Madrid, Spain). Once at LICA, we will test the individual gratings (already in sandwich with the windows) and once tested, we will carry out the final integration with the mounts (manufactured in Spanish workshops) and tested individually to prepare them for integration at the level of the System. Be aware that different coatings will be applied to the different windows so that perfect identification and Quality Control has to be carried out at both INAOE and Wasatch to assure no mistakes when recording the hologram. A mistake will invalidate the element since the VPHs have the transmission fully optimized to the central wavelength. There are 6 units (with 12 windows and 6 gratings in total).

MR elements: These elements are composed by two prisms and two windows with the VPH hologram recorded on the window. Initially, the elements were thought to be built without the windows, but we decided to use the windows for two reasons: to simplify the process at Wasatch since the prisms are too large to record the holograms and to optimize the thermal behavior of the gratings (better with Fused Silica windows - in previous design phases the windows were planned to be done in BK7. At the time of the OCDR the FS option was already presented). The windows follow the same steps as in the case of the LR elements except for the fact that the MR windows do not need to be coated. This shortens the path of the windows manufacturing. The prisms ( 2 per unit) shall be polished at INAOE and coated at CIO.

A decision made before the OCDR was to use the same Apex angle for all the 20 prisms of the 10 MR units. This eases manufacturing and avoid risks of mistakes with the prisms and the coating since each prism has to be coated with its own customized coating. A mistake in this process does not have impact on the final performance since geometrically and physically (material) all the prisms are identical.

A pair of BK7 prisms identical to those of PBM2Y shall be manufactured at INAOE for testing and essays the process, including the handling of these heavy and large prisms. Also these dummy prisms will be polished with the same tooling as the final ones. Once finished, each pair of prisms will be sent directly to LICA (Madrid, Spain). The tests of individual prisms and gratings (sandwiched between the windows) as well as the coupling between prisms and windows and the integration and tests of the whole units shall be done by FRACTAL at LICA. The dummy prisms could be sent to Madrid (TBC) to allow the essay of the coupling and handling of the final units. There are 10 units (with 20 prisms, 20 windows and 10 gratings in total).

HR elements: These units are identical to the MR units except for the Apex angle, which is different in each of the $2 \mathrm{HR}$ elements, and of course very different from the Apex prism of MR units. At the time of the OCDR we had decided to have the windows coated, but after a more detailed understanding of the refraction index variation in the hologram we have reached to the conclusion that the coating is not needed so that in this sense are identical to the MR ones. Due to the different Apex angle, another pair of BK7 prisms will be manufactured and tested to essay the process of prism manufacturing. 
We have defined a sequence for the production of the LR gratings. This sequence will imply that some windows will be waiting in the queue since all the windows cannot be manufactured in parallel. For example, the first three elements to be manufactured (for which we have already ordered the blanks) are HR-R, MR-U and LR-Z.

The first element of the LRs to be manufactured will be the LR-Z, whose complete milestone list is given in Figure 8 . The table shows all the milestones as a function of the time, from the early steps to the final ones.

\begin{tabular}{|c|c|c|c|}
\hline Date & Name & Parent date & Parent name \\
\hline 2013-11-20 & OP: FAB-INAOE. Fused Silica. VPH890-LR (LR-Z). Windows blanks. Ordering & & \\
\hline 2014-03-20 & $\begin{array}{l}\text { OP: FAB-INAOE. Fused Silica. VPH890-LR (LR-Z). Windows blanks. Arrival at } \\
\text { INAOE }\end{array}$ & & \\
\hline 2014-04-30 & $\begin{array}{l}\text { OP: FAB-INAOE. Fused Silica. VPH890-LR (LR-Z). Windows blanks. Shipping to } \\
\text { CIO }\end{array}$ & & \\
\hline 2014-04-30 & OP: FAB-CIO. Coating. Design and tests. Start. Fused Silica. VPH890-LR (LR-Z) & & \\
\hline 2014-05-04 & OP: FAB-CIO. Fused Silica. VPH890-LR (LR-Z). Windows blanks. Arrival at CIO & 2014-04-30 & $\begin{array}{l}\text { OP: FAB-INAOE. Fused Silica. VPH890-LR (LR-Z). Windows blanks. Shipping to } \\
\text { CIO }\end{array}$ \\
\hline \multirow[t]{2}{*}{ 2014-05-30 } & OP: FAB-CIO. Coating. Design and tests. End. Fused Silica. VPH890-LR (LR-Z). & 2014-04-30 & OP: FAB-CIO. Coating. Design and tests. Start. Fused Silica. VPH890-LR (LR-Z) \\
\hline & & 2014-03-16 & OP: FAB-CIO. Arrival. Coating supplies and material \\
\hline \multirow[t]{2}{*}{ 2014-06-10 } & OP: FAB-CIO. Fused Silica. VPH890-LR (LR-Z). Window1. Start polishing & 2014-06-09 & OP: FAB-CIO. Fused Silica. VPH410-MR (MR-U). Window2. End polishing \\
\hline & & 2014-05-04 & OP: FAB-CIO. Fused Silica. VPH890-LR (LR-Z). Windows blanks. Arrival at CIO \\
\hline 2014-06-17 & OP: FAB-CIO. Fused Silica. VPH890-LR (LR-Z). Window1. End polishing & 2014-06-10 & OP: FAB-CIO. Fused Silica. VPH890-LR (LR-Z). Window1. Start polishing \\
\hline \multirow[t]{2}{*}{ 2014-06-18 } & OP: FAB-CIO. Fused Silica. VPH890-LR (LR-Z). Window1. Start coating & 2014-06-17 & OP: FAB-CIO. Fused Silica. VPH890-LR (LR-Z). Window1. End polishing \\
\hline & & 2014-05-30 & OP: FAB-CIO. Coating. Design and tests. End. Fused Silica. VPH890-LR (LR-Z). \\
\hline 2014-06-19 & OP: FAB-CIO. Fused Silica. VPH890-LR (LR-Z). Window2. Start polishing & 2014-06-17 & OP: FAB-CIO. Fused Silica. VPH890-LR (LR-Z). Window1. End polishing \\
\hline 2014-06-25 & OP: FAB-CIO. Fused Silica. VPH890-LR (LR-Z). Window1. End coating & 2014-06-18 & OP: FAB-CIO. Fused Silica. VPH890-LR (LR-Z). Window1. Start coating \\
\hline 2014-06-26 & OP: FAB-CIO. Fused Silica. VPH890-LR (LR-Z). Window2. End polishing & 2014-06-19 & OP: FAB-CIO. Fused Silica. VPH890-LR (LR-Z). Window2. Start polishing \\
\hline \multirow[t]{3}{*}{ 2014-06-27 } & OP: FAB-CIO. Fused Silica. VPH890-LR (LR-Z). Window2. Start coating & 2014-06-26 & OP: FAB-CIO. Fused Silica. VPH890-LR (LR-Z). Window2. End polishing \\
\hline & & 2014-06-25 & OP: FAB-CIO. Fused Silica. VPH890-LR (LR-Z). Window1. End coating \\
\hline & & 2014-05-30 & OP: FAB-CIO. Coating. Design and tests. End. Fused Silica. VPH890-LR (LR-Z). \\
\hline 2014-07-04 & OP: FAB-CIO. Fused Silica. VPH890-LR (LR-Z). Window2. End coating & 2014-06-27 & OP: FAB-CIO. Fused Silica. VPH890-LR (LR-Z). Window2. Start coating \\
\hline 2014-07-07 & $\begin{array}{l}\text { OP: FAB-CIO. Fused Silica. VPH890-LR (LR-Z). Windows pair. Shipping to } \\
\text { INAOE }\end{array}$ & 2014-07-04 & OP: FAB-CIO. Fused Silica. VPH890-LR (LR-Z). Window2. End coating \\
\hline 2014-07-09 & $\begin{array}{l}\text { OP: FAB-INAOE. Fused Silica. VPH890-LR (LR-Z). Windows pair. Arrival at } \\
\text { INAOE }\end{array}$ & 2014-07-07 & OP: FAB-CIO. Fused Silica. VPH890-LR (LR-Z). Windows pair. Shipping to INAOE \\
\hline \multirow[t]{2}{*}{ 2014-07-16 } & $\begin{array}{l}\text { OP: FAB-INAOE. Fused Silica. VPH890-LR (LR-Z). Windows pair. Identification } \\
\text { and packaging done }\end{array}$ & 2014-07-09 & $\begin{array}{l}\text { OP: FAB-INAOE. Fused Silica. VPH890-LR (LR-Z). Windows pair. Arrival at } \\
\text { INAOE }\end{array}$ \\
\hline & & 2014-06-21 & OP: FAB-INAOE. Windows Packaging Boxes. Arrival at INAOE \\
\hline 2014-07-17 & $\begin{array}{l}\text { OP: FAB-INAOE. Fused Silica. VPH890-LR (LR-Z). Windows pair. Ready for } \\
\text { shipping }\end{array}$ & 2014-07-16 & $\begin{array}{l}\text { OP: FAB-INAOE. Fused Silica. VPH890-LR (LR-Z). Windows pair. Identification } \\
\text { and packaging done }\end{array}$ \\
\hline 2014-07-18 & $\begin{array}{l}\text { OP: FAB-INAOE. Fused Silica. VPH890-LR (LR-Z). Windows pair. Shipping to } \\
\text { Wasatch Photonics }\end{array}$ & 2014-07-17 & $\begin{array}{l}\text { OP: FAB-INAOE. Fused Silica. VPH890-LR (LR-Z). Windows pair. Ready for } \\
\text { shipping }\end{array}$ \\
\hline 2014-08-01 & $\begin{array}{l}\text { OP: FAB-WAS. Fused Silica. VPH890-LR (LR-Z). Windows pair. Arrival at } \\
\text { Wasatch Photonics }\end{array}$ & 2014-07-18 & $\begin{array}{l}\text { OP: FAB-INAOE. Fused Silica. VPH890-LR (LR-Z). Windows pair. Shipping to } \\
\text { Wasatch Photonics }\end{array}$ \\
\hline 2014-08-22 & OP: FAB-WAS. VPH890-LR (LR-Z). VPH hologram and sandwich & 2014-08-01 & $\begin{array}{l}\text { OP: FAB-WAS. Fused Silica. VPH890-LR (LR-Z). Windows pair. Arrival at } \\
\text { Wasatch Photonics }\end{array}$ \\
\hline 2014-08-23 & OP: FAB-WAS. VPH890-LR (LR-Z). VPH Shipping to UCM & 2014-08-22 & OP: FAB-WAS. VPH890-LR (LR-Z). VPH hologram and sandwich \\
\hline 2014-09-13 & OP: AIV-UCM. VPH890-LR (LR-Z). Arrival at UCM & 2014-08-23 & OP: FAB-WAS. VPH890-LR (LR-Z). VPH Shipping to UCM \\
\hline 2014-09-27 & OP: AIV-UCM. VPH890-LR (LR-Z). Assembly and Tests. Start & 2014-09-13 & OP: AIV-UCM. VPH890-LR (LR-Z). Arrival at UCM \\
\hline 2014-10-11 & OP: AIV-UCM. VPH890-LR (LR-Z). Assembly and Test. End & 2014-09-27 & OP: AIV-UCM. VPH890-LR (LR-Z). Assembly and Tests. Start \\
\hline $2014-10-12$ & OP: AIV-UCM. VPH890-LR (LR-Z). Ready for Integration & 2014-10-11 & OP: AIV-UCM. VPH890-LR (LR-Z). Assembly and Test. End \\
\hline
\end{tabular}

Figure 8. MANATEE output exported in an xls file. LR-Z element. Example of the schedule detail and links. 
The critical path of this particular grating is given in Figure 9 and lasts 165 days.

\begin{tabular}{|c|c|c|c|c|}
\hline Date & Name & $\begin{array}{l}\text { Parent } \\
\text { date }\end{array}$ & Parent name & length (days) \\
\hline 2014-10-12 & OP: AIV-UCM. VPH890-LR (LR-Z). Ready for Integration & 2014-10-11 & OP: AIV-UCM. VPH890-LR (LR-Z). Assembly and Test. End & 1 \\
\hline 2014-10-11 & OP: AIV-UCM. VPH890-LR (LR-Z). Assembly and Test. End & 2014-09-27 | & OP: AIV-UCM. VPH890-LR (LR-Z). Assembly and Tests. Start & 14 \\
\hline 2014-09-27 & OP: AIV-UCM. VPH890-LR (LR-Z). Assembly and Tests. Start & 2014-09-13 & OP: AIV-UCM. VPH890-LR (LR-Z). Arrival at UCM & 14 \\
\hline 2014-09-13 & OP: AIV-UCM. VPH890-LR (LR-Z). Arrival at UCM & $2014-08-23$ & OP: FAB-WAS. VPH890-LR (LR-Z). VPH Shipping to UCM & 21 \\
\hline 2014-08-23 & OP: FAB-WAS. VPH890-LR (LR-Z). VPH Shipping to UCM & 2014-08-22 & OP: FAB-WAS. VPH890-LR (LR-Z). VPH hologram and sandwich & 1 \\
\hline 2014-08-22 & OP: FAB-WAS. VPH890-LR (LR-Z). VPH hologram and sandwich & 2014-08-01 & $\begin{array}{l}\text { OP: FAB-WAS. Fused Silica. VPH890-LR (LR-Z). Windows pair. } \\
\text { Arrival at Wasatch Photonics }\end{array}$ & 21 \\
\hline 2014-08-01 & $\begin{array}{l}\text { OP: FAB-WAS. Fused Silica. VPH890-LR (LR-Z). Windows pair. Arrival at } \\
\text { Wasatch Photonics }\end{array}$ & 2014-07-18 & $\begin{array}{l}\text { OP: FAB-INAOE. Fused Silica. VPH890-LR (LR-Z). Windows pair. } \\
\text { Shipping to Wasatch Photonics }\end{array}$ & 14 \\
\hline 2014-07-18 & $\begin{array}{l}\text { OP: FAB-INAOE. Fused Silica. VPH890-LR (LR-Z). Windows pair. Shipping to } \\
\text { Wasatch Photonics }\end{array}$ & 2014-07-17 & $\begin{array}{l}\text { OP: FAB-INAOE. Fused Silica. VPH890-LR (LR-Z). Windows pair. } \\
\text { Ready for shipping }\end{array}$ & 1 \\
\hline 2014-07-17 & $\begin{array}{l}\begin{array}{l}\text { OP: FAB-INAOE. Fused Silica. VPH890-LR (LR-Z). Windows pair. Ready for } \\
\text { shipping }\end{array} \\
\end{array}$ & 2014-07-16 & $\begin{array}{l}\text { OP: FAB-INAOE. Fused Silica. VPH890-LR (LR-Z). Windows pair. } \\
\text { Identification and packaging done }\end{array}$ & 1 \\
\hline \multirow[t]{2}{*}{ 2014-07-16 } & $\begin{array}{l}\text { OP: FAB-INAOE. Fused Silica. VPH890-LR (LR-Z). Windows pair. } \\
\text { Identification and packaging done }\end{array}$ & 2014-07-09 & $\begin{array}{l}\text { OP: FAB-INAOE. Fused Silica. VPH890-LR (LR-Z). Windows pair. } \\
\text { Arrival at INAOE }\end{array}$ & 7 \\
\hline & & 2014-06-21 & OP: FAB-INAOE. Windows Packaging Boxes. Arrival at INAOE & 25 \\
\hline 2014-07-09 & $\begin{array}{l}\text { OP: FAB-INAOE. Fused Silica. VPH890-LR (LR-Z). Windows pair. Arrival at } \\
\text { INAOE }\end{array}$ & 2014-07-07 & $\begin{array}{l}\text { OP: FAB-CIO. Fused Silica. VPH890-LR (LR-Z). Windows pair. } \\
\text { Shipping to INAOE }\end{array}$ & 2 \\
\hline 2014-07-07 & $\begin{array}{l}\text { OP: FAB-CIO. Fused Silica. VPH890-LR (LR-Z). Windows pair. Shipping to } \\
\text { INAOE }\end{array}$ & 2014-07-04 & $\begin{array}{l}\text { OP: FAB-CIO. Fused Silica. VPH890-LR (LR-Z). Window2. End } \\
\text { coating }\end{array}$ & 3 \\
\hline 2014-07-04 & OP: FAB-CIO. Fused Silica. VPH890-LR (LR-Z). Window2. End coating & 2014-06-27 & $\begin{array}{l}\text { OP: FAB-CIO. Fused Silica. VPH890-LR (LR-Z). Window2. Start } \\
\text { coating }\end{array}$ & 7 \\
\hline \multirow[t]{3}{*}{ 2014-06-27 } & OP: FAB-CIO. Fused Silica. VPH890-LR (LR-Z). Window2. Start coating & 2014-06-26 & $\begin{array}{l}\text { OP: FAB-CIO. Fused Silica. VPH890-LR (LR-Z). Window2. End } \\
\text { polishing }\end{array}$ & 1 \\
\hline & & 2014-06-25 & $\begin{array}{l}\text { OP: FAB-CIO. Fused Silica. VPH890-LR (LR-Z). Window1. End } \\
\text { coating }\end{array}$ & 2 \\
\hline & & 2014-05-30 & $\begin{array}{l}\text { OP: FAB-CIO. Coating. Design and tests. End. Fused Silica. VPH890 } \\
\text { LR (LR-Z). }\end{array}$ & 28 \\
\hline 2014-06-26 & OP: FAB-CIO. Fused Silica. VPH890-LR (LR-Z). Window2. End polishing & 2014-06-19 & $\begin{array}{l}\text { OP: FAB-CIO. Fused Silica. VPH890-LR (LR-Z). Window2. Start } \\
\text { polishing }\end{array}$ & 7 \\
\hline 2014-06-19 & OP: FAB-CIO. Fused Silica. VPH890-LR (LR-Z). Window2. Start polishing & 2014-06-17 & $\begin{array}{l}\text { OP: FAB-CIO. Fused Silica. VPH890-LR (LR-Z). Window1. End } \\
\text { polishing }\end{array}$ & 2 \\
\hline 2014-06-17 & OP: FAB-CIO. Fused Silica. VPH890-LR (LR-Z). Window1. End polishing & 2014-06-10 & $\begin{array}{l}\text { OP: FAB-CIO. Fused Silica. VPH890-LR (LR-Z). Window1. Start } \\
\text { polishing }\end{array}$ & 7 \\
\hline \multirow[t]{2}{*}{ 2014-06-10 } & OP: FAB-CIO. Fused Silica. VPH890-LR (LR-Z). Window1. Start polishing & 2014-06-09 & $\begin{array}{l}\text { OP: FAB-CIO. Fused Silica. VPH410-MR (MR-U). Window2. End } \\
\text { polishing }\end{array}$ & 1 \\
\hline & & 2014-05-04 & $\begin{array}{l}\text { OP: FAB-CIO. Fused Silica. VPH890-LR (LR-Z). Windows blanks. } \\
\text { Arrival at CIO }\end{array}$ & 37 \\
\hline 2014-06-09 & OP: FAB-CIO. Fused Silica. VPH410-MR (MR-U). Window2. End polishing & 2014-06-02 & $\begin{array}{l}\text { OP: FAB-CIO. Fused Silica. VPH410-MR (MR-U). Window2. Start } \\
\text { polishing }\end{array}$ & 7 \\
\hline 2014-06-02 & OP: FAB-CIO. Fused Silica. VPH410-MR (MR-U). Window2. Start polishing & 2014-06-01 & $\begin{array}{l}\text { OP: FAB-CIO. Fused Silica. VPH410-MR (MR-U). Window1. End } \\
\text { polishing }\end{array}$ & 1 \\
\hline 2014-06-01 & OP: FAB-CIO. Fused Silica. VPH410-MR (MR-U). Window1. End polishing & $2014-05-25$ & $\begin{array}{l}\text { OP: FAB-CIO. Fused Silica. VPH410-MR (MR-U). Window1. Start } \\
\text { polishing }\end{array}$ & 7 \\
\hline \multirow[t]{2}{*}{ 2014-05-25 } & OP: FAB-CIO. Fused Silica. VPH410-MR (MR-U). Window1. Start polishing & $2014-05-24$ & $\begin{array}{l}\text { OP: FAB-CIO. Fused Silica. VPH665-HR (HR-R). Window2. End } \\
\text { polishing }\end{array}$ & 1 \\
\hline & & 2014-05-07 & $\begin{array}{l}\text { OP: FAB-CIO. Fused Silica. VPH410-MR (MR-U). Windows blanks. } \\
\text { Arrival at CIO }\end{array}$ & 18 \\
\hline 2014-05-24 & OP: FAB-CIO. Fused Silica. VPH665-HR (HR-R). Window2. End polishing & 2014-05-17 & $\begin{array}{l}\text { OP: FAB-CIO. Fused Silica. VPH665-HR (HR-R). Window2. Start } \\
\text { polishing }\end{array}$ & 7 \\
\hline 2014-05-17 & OP: FAB-CIO. Fused Silica. VPH665-HR (HR-R). Window2. Start polishing & 2014-05-16 & $\begin{array}{l}\text { OP: FAB-CIO. Fused Silica. VPH665-HR (HR-R). Window1. End } \\
\text { polishing }\end{array}$ & 1 \\
\hline 2014-05-16 & OP: FAB-CIO. Fused Silica. VPH665-HR (HR-R). Window1. End polishing & 2014-05-09 & $\begin{array}{l}\text { OP: FAB-CIO. Fused Silica. VPH665-HR (HR-R). Window1. Start } \\
\text { polishing }\end{array}$ & 7 \\
\hline 2014-05-09 & OP: FAB-CIO. Fused Silica. VPH665-HR (HR-R). Window1. Start polishing & 2014-05-02 & $\begin{array}{l}\text { OP: FAB-CIO. Fused Silica. VPH665-HR (HR-R). Windows blanks. } \\
\text { Arrival at CIO }\end{array}$ & 7 \\
\hline \multirow[t]{2}{*}{ 2014-05-02 } & $\begin{array}{l}\text { OP: FAB-CIO. Fused Silica. VPH665-HR (HR-R). Windows blanks. Arrival at } \\
\text { CIO }\end{array}$ & 2014-04-30 & $\begin{array}{l}\text { OP: FAB-INAOE. Fused Silica. VPH665-HR (HR-R). Windows } \\
\text { blanks. Shipping to CIO }\end{array}$ & 2 \\
\hline & & & & 165 \\
\hline
\end{tabular}

Figure 9. MANATEE output exported in an xls file. LR-Z element. Example of the schedule detail and links.

The time to complete the whole cycle of a LR grating is approximately of 125 days ( $\sim 4$ months). A fine-tuning will be done in the plan as soon as we complete the first cycle to try to shorten the calendar. We have done the same kind of analysis for each of the 18 pupil elements. The first MR to be produced (MR-U) has a production cycle of 293 days, since this unit will be waiting until the tests on the dummy prisms will be finished. For any other unit the time would shorten in at least 5 months (150 days), time to develop the first pair of dummy prisms, being the whole process of about 140 days in total. INAOE plans to use two machines simultaneously and we are studying strategies to shorten the process as much as possible. It is important to remark that the delivery time of the blanks is 7.5 months. 


\subsection{WP 9: Cryostat}

The calendar is consistent with a delivery of the cryostat together with the main optics (camera and cryostat) at the end of March 2015. The critical path is driven by the money availability to order the materials and to start manufacturing.

\subsection{WP 10: Control System}

The Control System scope and functionality has been documented and planned linked to the Use Cases (UC). Also, the UC have been linked to the milestones of the different subsystems when this functionality is required.

\subsection{WP 11: AIV at LICA}

The AIV will be done at LICA laboratory at UCM (Madrid). We list below the calendar. Green dates are the contractual milestones with GRANTECAN.

\begin{tabular}{|l|l|}
\hline \multicolumn{1}{|c|}{ Date } & \multicolumn{1}{c|}{ Name } \\
\hline $2014-10-13$ & AIV: First LR (LR-Z) ready for AIV \\
\hline $2014-12-31$ & AIV: Mechanism Control System (I) tested. Functionality for AIV \\
\hline $2015-01-31$ & Preparation for MEGARA Acceptance (PFA). Documentation Delivery \\
\hline $2015-02-20$ & AIV: All LR. Ready for AIV \\
\hline $2015-03-01$ & AIV: Pipeline Control System (I) tested. Functionality for AIV \\
\hline $2015-03-01$ & AIV: Spectrograph Mechanism integrated and tested \\
\hline $2015-03-02$ & Preparation for MEGARA Acceptance (PFA). Review process closed \\
\hline $2015-03-20$ & AIV: First MR (MR-U) ready for AIV \\
\hline $2015-03-21$ & AIV: First HR (HR-R) ready for AIV \\
\hline $2015-04-19$ & AIV: Cryostat at UCM \\
\hline $2015-04-19$ & AIV: Main Optics at UCM \\
\hline $2015-05-01$ & AIV: System Integration and Alignment. Start. \\
\hline $2015-05-16$ & AIV: LCB bundle ready for AIV \\
\hline $2015-05-18$ & AIV: Cryostat-DAS. Ready for AIV \\
\hline $2015-05-25$ & AIV: Camera-Cryostat ready for AIV \\
\hline $2015-05-30$ & AIV: All HR. Ready for AIV \\
\hline $2015-07-10$ & AIV: System Integration and Alignment. End \\
\hline $2015-08-20$ & AIV: MOS bundle ready for AIV \\
\hline $2015-09-30$ & AIV: Control System Funcionality completed \\
\hline $2015-11-30$ & AIV: All MR. Ready for AIV \\
\hline $2015-11-30$ & AIV: AIV at LICA. End \\
\hline $2016-02-28$ & Laboratory Acceptance Review (LAR) \\
\hline
\end{tabular}

Figure 10. MANATEE output exported in an xls file. AIV milestone list

\section{CONCLUSIONS}

We have discussed in this paper the current status of the MEGARA Management Plan and its tracking.

The UCM as leading institution is ready to provide the needed effort and resources to develop MEGARA Project. In addition INAOE, UPM and IAA-CSIC are MEGARA partners with committed resources and in-kind contributions to the project. The PI has all the support from his institution UCM. Thanks to his scientific excellence and personal skills, MEGARA has kept a Science Team and an Instrument Team committed to put the necessary effort to become MEGARA to a fact. This has been demonstrated during the Conceptual, Preliminary and Detailed Design phases of the project. 
The structure is composed by senior PI, PM, SE and WP managers; most of them with a PhD and the others, experienced engineers, who coordinate different groups with a majority of senior engineers. The PM and the SE have the necessary skills and professional expertise to coordinate the Instrument Team in the managerial and technical aspects. The WP managers have driven their respective teams to design the different subsystems. The team is the same since the beginning of the project and has demonstrated to be able to work together, and a high level of motivation and commitment.

Regarding scope, MEGARA has been fully designed and is ready for manufacturing. The instrument is based on a Fiber Unit system, coupled to the telescope at the Folded-Cass focus, with three main modes: LCB, MOS (fully funded) and SCB (funds not available yet), and one spectrograph (located on the Nasmyth platform) providing three spectral resolutions, with $6 \mathrm{LR}, 10 \mathrm{MR}$ and $2 \mathrm{HR}$ that cover the whole wavelength range at low and mid resolution.

MEGARA has been designed with known solutions and no shop-stoppers have been identified. MEGARA has successfully passed all previous review milestones successfully. The purchase of part of the blanks was done last year and the optics manufacturing has already started at both INAOE and CIO workshops in Mexico ${ }^{6}$. The project is technically controlled with System Engineering procedures and the discipline is well followed by the whole team.

The total cost of this ambitious scientific project has been calculated in $11.8 \mathrm{M} €$, distributed in money (6.50 M€) and inkind $(5.30 \mathrm{M} €$ ) contributions. The money needed today to finish the project is $5.1 \mathrm{M} €$, from which the current contract with GRANTECAN covers $4.49 \mathrm{M} €$. The UCM is developing a plan to get the missing $0.61 \mathrm{M} €$ along the next year. No de-scoping plan exists except for removing the SCB if needed. The budget has a high degree of reliability since $90 \%$ of the estimates are based in firm fixed quotations and committed prices of the engineering services of both companies and partners. The major project driver for schedule and consequently budget is having an appropriate cash flow for the funds coming from GRANTECAN's contract. The project expenses have been traced to the contractual payment milestones.

For the in-kind contribution the Consortium will receive 301.28 hours of Guaranteed Time, being this amount of money far from the compensation of the real work carried out at the Consortium centers. The Science team is working hard in preparing the observations for both, commissioning and scientific exploitation of the awarded Guaranteed Time.

A detailed plan for procuring, manufacturing, integrating and test each subsystem, has been established. All subsystems' delivery time are pretty well known what allows estimating the schedule quite precisely. A complete AIV plan at the level of the System has also been developed. The schedule is tight until the Laboratory Acceptance (February 2016). The current contract with GRANTECAN commits an arrival to the GTC before December 2016 and the end of the commissioning in April 2017. The project control tool MANATEE allows a precise control of the milestones and the links among them. Consequently the critical path at the level of subsystems and at the level of the complete system is automatically updated when the milestones are reviewed. The tool allows task reporting, actions tracking and budget update in a very simple way and all data are accessible to the team on real time.

The plan pursues to make MEGARA a fact, keeping the performance according to specifications, building it with the available budget and being on time when required for installation. The team is committed to make MEGARA successes.

\section{REFERENCES}

[1] Gil de Paz, et al., "MEGARA: a new generation optical spectrograph for GTC," Proc. SPIE 9147, 23 (2014)

[2] Pérez-Calpena et al., "System engineering at the MEGARA project," Proc. SPIE 9150, 81 (2014)

[3] Pérez-Calpena, A., et al., "MEGARA Focal Plane Subsystems," Proc. SPIE 8446, 206 (2012)

[4] Pérez-Calpena et al., "MEGARA fiber bundles," Proc. SPIE 9147, 211 (2014)

[5] Carrasco, E., et al., "MEGARA Spectrograph Optics," Proc. SPIE 8446, 203 (2012)

[6] Carrasco etal. , "MEGARA Optical manufacturing process," Proc. SPIE 9147, 264 (2014)

[7] Castillo etal. , "MEGARA main optics optomechanics," Proc. SPIE 9147, 214 (2014)

[8] Ferrusca etal. , "MEGARA cryostat advanced design," Proc. SPIE 9147, 254 (2014)

[9] Pérez-Calpena, A.; Mujica-Alvarez, E.; Osinde-Lopez, J. \&, "FRACTAL System \& Project suite: engineering tools for improving development and operation of the systems," Proc. SPIE 7017, 1 (2008)

[10] García-Vargas, M.; Mujica-Alvarez, E. \& Pérez-Calpena, A. "Astronomical large projects managed with MANATEE: MANAgement Tool for Effective Engineering," Proc. SPIE 8449,1 (2012)

[11] Mujica-Alvarez, E., Pérez-Calpena, A. and García-Vargas, M.L. "SUMO: Operation and Maintenance Management web tool for astronomical observatories," Proc. SPIE 9149, 53 (2014) 